\title{
Applying the Bacterial Meningitis Score in Neonates Diagnosed Meningitis: A Single Center Experience
}

Sun Young Park, M.D., Kyoo Hyun Seo, M.D., Jae Min Lee, M.D., Eun Sil Lee, M.D., and Saeyoon Kim, M.D. Department of Pediatrics, Yeungnam University College of Medicine, Daegu, Korea

\section{ABSTRACT}

Purpose: To identify the factors associated with differential diagnosis of neonatal bacterial meningitis at the earliest opportunities possible and to evaluate the value of the bacterial meningitis score especially in neonates.

Methods: We conducted a single-center, retrospective study of neonates diagnosed meningitis at our hospital between January 2000 and March 2014. We compared the general characteristics, clinical manifestations, laboratory findings, bacterial meningitis scores between the bacterial group and the aseptic group.

Results: Bacterial meningitis differs significantly from aseptic meningitis in platelet count, the cerebrospinal fluid polymorphonuclear leukocyte count, and the serum protein including also the albumin $(P<0.05)$. Except two infants, the bacterial meningitis score over 2 accurately predict bacterial meningitis in the other 11 infants.

Conclusion: The bacterial meningitis score appears highly useful to identify neonatal infants with bacterial meningitis. However, its diagnostic and prognostic value is just 'adjunctive', because low score cannot rule out bacterial meningitis.

Key words: Neonates, Aseptic meningitis, Bacterial meningitis

\section{INTRODUCTION}

Meningitis is more common in the neonatal period than at any other time ${ }^{1)}$. The newborn is particularly susceptible to infection as the immature immune system is deficient in humoral and cellular immune responses in phagocytic and in complement functions ${ }^{2}$.

Neonatal bacterial meningitis continues to be a severe disease with high morbidity, despite the fact that over the last few decades its mortality rates have reduced. Around 20$58 \%$ of survivors showed neurological sequelae ${ }^{3,4}$. Early recognition of infants at risk for poor prognosis would be helpful in providing prompt management and identifying those who warrant long-term follow up and early intervention.

The bacterial meningitis score (BMS) has been designed to identify children at low (BMS=0) risk of bacterial meningitis so that they can be considered for outpatient management if they are otherwise well appearing and have adequate clinical follow-up. Its calculation is simple; it is based on five different items: gram stain, seizure at or before
Received: 3 August 2016

Revised: 25 October 2016

Accepted: 28 October 2016

Correspondence to: Saeyoon Kim

Department of Pediatrics, Yeungnam University College of Medicine, 170 Hyeonchung-ro, Nam-gu, Daegu 42415 , Korea

Tel: +82-53-620-3533

Fax: +82-53-629-2252

E-mail: sysnow88@hanmail.net

Copyright(c)

By Korean Society of Neonatology.

All right reserved.

This is an Open-Access article distributed under the terms of the Creative Commons Attribution Non-Commercial License (http://creativecommons.org/licenses/ by-nc/4.0), which permits unrestricted non-commercial use, distribution, and reproduction in any medium, provided the original work is properly cited. 
presentation, peripheral white blood cell count (WBC), cerebrospinal fluid (CSF) WBC and CSF protein concentration ${ }^{5}$. This score has been validated in several studies with high sensitivity and negative predictive value $\mathrm{e}^{5-12)}$.

In those studies, most recommended the BMS not be applied to the patients younger than 2 months of age for whom the BMS may be less accurate, and who may not be appropriate candidates for outpatient management. However, predictive value of the BMS has not been evaluated in single neonate group.

To evaluate the performance of the BMS to discriminate infant with bacterial from aseptic meningitis, we assembled a cohort of newborn with meningitis evaluated at a single neonatal intensive care unit located in Korea.

\section{MATERIALS AND METHODS}

A retrospective cohort study of patients who admitted to the neonatal intensive care unit (NICU) of the Yeungnam University Medical Center (YUMC) in Daegu from January 2000 to March 2014 was conducted and their total count was 5,548.

We reviewed the medical records of 73 pediatric patients finally diagnosed with meningitis through CSF study, among patients initially presented clinical manifestations of neonatal sepsis and conducted retrospective comparative analysis between bacterial group and aseptic group.

The diagnosis of meningitis was based on either one of the following criteria: positive culture of CSF and/or presence of CSF pleocytosis $\left(\geq 25 / \mathrm{mm}^{3}\right)$ and/or presence of positive latex agglutination test for Streptococcus pneumoniae, Neisseria meningitides, Haemophilus influenza type b or group B streptococcus in the CSF and/or positive PCR for Enterovirus or Herpes simplex virus I in the CSF and/or positive blood culture associated with a CSF pleocytosis $\left(\geq 25 / \mathrm{mm}^{3}\right)^{13)}$.

All blood cultures were performed before starting antibiotics from radial arterial puncture with due aseptic precautions after cleaning with ethanol swab. Infants with blood contamination (more than one agent in the same culture) were excluded.

Patients were categorized as bacterial group if either of the following two criteria were met: 1 ) the CSF culture was positive for a bacterial pathogen; or 2) the blood culture was positive for a bacterial pathogen ${ }^{14)}$.

Patients were categorized as aseptic group if they met diagnostic criteria of meningitis with negative bacterial cultures, so was diagnosed as aseptic meningitis.

Patients who had previously diagnosed encephalopathy before infection, like hemorrhage or concussion with a history of trauma, vascular anomaly, and embryologic problems were excluded. We also excluded patients with insufficient medical records.

We collected the following variables at the time of visit by a review of the computerized and/or written medical records: gender, clinical symptoms, laboratory findings at admission, CSF study. Then, we calculated and compared the BMS between two groups. Mann-Whitney test and Fisher's exact test was conducted using SPSS version 22.0 (IBM Co., Armonk, NY, USA). We considered statistically significant at $P<0.05$. The study protocol was approved by the institutional review board of YUMC (IRB No. YUMC 2015-06-050).

\section{RESULTS}

Among the 5,548 patients admitted to the NICU of the YUMC over about 14-year study period, we identified 73 infants with CSF pleocytosis who were finally diagnosed meningitis. But three were excluded due to insufficient medical records. Considering the 73 infants included, the incidence of meningitis was $1.3 \%(73 / 5,548)$ and the mortality rate was $1.37 \%(1 / 73)$. The 70 patients were composed of 57 with aseptic meningitis and 13 with bacterial meningitis. In bacterial group, 4 were male (31\%) and in aseptic group, 34 were male (60\%). Male prevalence was lower in bacterial group than aseptic group (31\% vs. $60 \%$ ); however there was no statistical significance (Table 1).

Mean gestational age (GA) at diagnosis of two groups was $37.9 \pm 2.2$ weeks and $38.7 \pm 2.0$ weeks each, and there was no difference between them. Sixty-two (88.6\%) were born at term (GA $\geq 37$ weeks) and eight infants were born preterm (GA<37 weeks). Among the latter, seven (10\%) infants were born between 33

Table 1. General Characteristics of Bacterial and Aseptic Groups

\begin{tabular}{lccc}
\hline & $\begin{array}{c}\text { Bacterial group } \\
(\mathrm{n}=13)\end{array}$ & $\begin{array}{c}\text { Aseptic group } \\
(\mathrm{n}=57)\end{array}$ & $P$-value \\
\hline Sex (M/F) & $4 / 9(31 \%)$ & $34 / 23(60 \%)$ & 0.059 \\
Gestational age (wks) & $37.9 \pm 2.2$ & $38.7 \pm 2.0$ & 0.195 \\
$<33$ (wks) & 0 & 1 & \\
$33-36$ & 3 & 4 & 0.282 \\
$\geq 37$ & 10 & 52 & \\
\hline
\end{tabular}

Plus-minus values are mean \pm SD. 
weeks and 36 weeks +6 days (late preterm), and one (1.4\%) infant was born before 33 weeks (very preterm) (Table 1 ).

We compared clinical and laboratory findings for patients with aseptic and bacterial meningitis (Tables 2-4). For clinical symptoms, fever was the one found the most followed by in the order of grunting, seizure, and vomiting, fontanelle bulging, and tachycardia. All patients in both group presented fever and no significant intergroup difference was found in the average of the daily maximum body temperature as it was $38.8 \pm 0.6^{\circ} \mathrm{C}$ in bacterial group and $38.7 \pm 0.5^{\circ} \mathrm{C}$ in aseptic group. Grunting was the second common symptom in both groups. Vomiting was presented from one patient (7.7\%) in bacterial group and five patients (8.8\%) in aseptic group. For fontanelle bulging, no infant in bacterial group presented the symptom whereas it was found from five infants in aseptic group. Despite of the higher frequencies for these two symptoms those that were presented in aseptic group, these were not statistically significant. Seizure was experienced by three infants in each group (Table 2).

The blood examination revealed that no intergroup difference

Table 2. Clinical Manifestations of Bacterial and Aseptic Groups

\begin{tabular}{lccc}
\hline & $\begin{array}{c}\text { Bacterial group } \\
(\mathrm{n}=13)\end{array}$ & $\begin{array}{c}\text { Aseptic group } \\
(\mathrm{n}=57)\end{array}$ & $P$-value \\
\hline Fever (highest) & $10(38.8 \pm 0.6)$ & $55(38.7 \pm 0.5)$ & 0.635 \\
Grunting & 5 & 25 & 0.723 \\
Vomiting & 1 & 5 & 1.000 \\
Tachycardia & 2 & 1 & 0.086 \\
Fontanelle bulging & 0 & 5 & 0.576 \\
Seizure & 3 & 3 & 0.073 \\
\hline
\end{tabular}

Plus-minus values are mean \pm SD.

Table 3. Comparison of Laboratory Findings between the Groups

\begin{tabular}{lccc}
\hline & $\begin{array}{c}\text { Bacterial group } \\
(\mathrm{n}=13)\end{array}$ & $\begin{array}{c}\text { Aseptic group } \\
(\mathrm{n}=57)\end{array}$ & $P$-value \\
\hline WBC $\left(/ \mathrm{mm}^{3}\right)$ & $13,322.3 \pm 6,208.1$ & $12,518.6 \pm 4,466.6$ & 0.446 \\
Hemoglobin $(\mathrm{g} / \mathrm{dL})$ & $13.1 \pm 2.5$ & $11.8 \pm 2.4$ & 0.066 \\
Platelet $(/ \mu \mathrm{L})$ & $362,154 \pm 191,228$ & $438,175 \pm 142,750$ & 0.035 \\
Glucose $(\mathrm{mg} / \mathrm{dL})$ & $114.7 \pm 33.3$ & $101.9 \pm 34.4$ & 0.172 \\
CRP $(\mathrm{mg} / \mathrm{dL})$ & $2.3 \pm 3.8$ & $0.7 \pm 0.9$ & 0.462 \\
AST $(\mathrm{IU} / \mathrm{L})$ & $35.6 \pm 13.9$ & $53.5 \pm 67.5$ & 0.832 \\
ALT $(\mathrm{IU} / \mathrm{L})$ & $18.0 \pm 7.3$ & $38.5 \pm 57.5$ & 0.008 \\
Total protein $(\mathrm{g} / \mathrm{dL})$ & $5.2 \pm 0.6$ & $5.7 \pm 0.5$ & 0.017 \\
Albumin $(\mathrm{g} / \mathrm{dL})$ & $3.5 \pm 0.4$ & $3.8 \pm 0.4$ & 0.043 \\
\hline
\end{tabular}

Plus-minus values are mean \pm SD.

Abbreviations: WBC, white blood cell count; CRP, C-reactive protein; AST, aspartate aminotransferase; ALT, alanine aminotransaminase.
$(P=0.446)$ was found in total leukocytes as it was $13,322.3 \pm 6,208.1$ $/ \mathrm{mm}^{3}$ and $12,518.6 \pm 4,466.6 / \mathrm{mm}^{3}$ for bacterial group and aseptic group, respectively. Likely, C-reactive protein was found as $2.3 \pm$ $3.8 \mathrm{mg} / \mathrm{dL}$ and $0.7 \pm 0.9 \mathrm{mg} / \mathrm{dL}$ for bacterial group and aseptic group respectively, showing no significance $(P=0.462)$. There were no intergroup differences found in the levels of hemoglobin and blood glucose. However, platelet count was higher $(P=0.035)$ in bacterial group as $362,154 \pm 191,228 / \mu \mathrm{L}$ compared to $438,175 \pm$ $142,750 / \mu \mathrm{L}$ in aseptic group. For liver function test, no intergroup difference was found for aspartate aminotransferase (AST) $(35.6 \pm 13.9 \mathrm{IU} / \mathrm{L}$ vs. $53.5 \pm 67.5 \mathrm{IU} / \mathrm{L}, P=0.832)$ whereas alanine aminotransaminase (ALT) was higher in aseptic group (18.0 \pm 7.3 $\mathrm{IU} / \mathrm{L}$ vs. $38.5 \pm 57.5 \mathrm{IU} / \mathrm{L}, P=0.008)$. Both total protein $(5.2 \pm 0.6 \mathrm{~g} /$ dL vs. $5.7 \pm 0.5 \mathrm{~g} / \mathrm{dL}, P=0.017)$ and albumin $(3.5 \pm 0.4 \mathrm{~g} / \mathrm{dL}$ vs. $3.8 \pm$ $0.4 \mathrm{~g} / \mathrm{dL}, P=0.043$ ) were higher in aseptic group (Table 3 ).

The cerebrospinal fluid examination revealed that no intergroup difference $(P=0.526)$ for white blood cell count as it was $334.4 \pm 728.2 / \mathrm{mm}^{3}$ in bacterial group and $238.4 \pm 239.5 / \mathrm{mm}^{3}$ in aseptic group; the proportion of the polymorphonuclear was higher in aseptic group $(63.2 \pm 32.0 \%$ in bacterial group vs. $33.8 \pm$ $30.8 \%$ in aseptic group, $P=0.003$ ). There was no intergroup difference found from the level of protein and glucose in the cerebrospinal fluid (Table 4).

Then, BMS was calculated for the study population (Table 4). The BMS could be applied to all of the 13 infants with bacterial meningitis, two had a very low risk BMS whereas no high risk BMS was found from the 57 infants with aseptic meningitis. Mean BMS was higher in bacterial group (1.8 \pm 1.1 in bacterial

Table 4. Comparison of Cerebrospinal Fluid Findings and Bacterial Meningitis Score between the Groups

\begin{tabular}{lccr}
\hline & $\begin{array}{c}\text { Bacterial group } \\
(\mathrm{n}=13)\end{array}$ & $\begin{array}{c}\text { Aseptic group } \\
(\mathrm{n}=57)\end{array}$ & $P$-value \\
\hline $\mathrm{WBC}\left(/ \mathrm{mm}^{3}\right)$ & $334.4 \pm 728.2$ & $238.4 \pm 239.5$ & 0.526 \\
poly $(\%)$ & $63.2 \pm 32.0$ & $33.8 \pm 30.8$ & 0.003 \\
Protein $(\mathrm{mg} / \mathrm{dL})$ & $197.0 \pm 264.2$ & $97.3 \pm 42.9$ & 0.656 \\
CSF/serum & $0.048 \pm 0.059$ & $0.017 \pm 0.007$ & 0.373 \\
Glucose $(\mathrm{mg} / \mathrm{dL})$ & $48.5 \pm 21.0$ & $51.0 \pm 21.1$ & 0.141 \\
CSF/serum & $0.5 \pm 0.2$ & $0.5 \pm 0.2$ & 0.311 \\
BMS & $1.8 \pm 1.1$ & $0.5 \pm 0.5$ & $<0.001$ \\
0 & 2 & 28 & \\
1 & 4 & 29 & \\
$\geq 2$ & 7 & 0 & \\
\hline
\end{tabular}

Plus-minus values are mean \pm SD.

Abbreviations: WBC, white blood cell count; CSF, cerebrospinal fluid; BMS, bacterial meningitis score 
Table 5. Clinical Characteristics of Bacterial Group

\begin{tabular}{|c|c|c|c|c|c|c|}
\hline $\begin{array}{l}\text { Patient } \\
\text { number }\end{array}$ & $\begin{array}{c}\text { CSF WBC } \\
\text { (poly,\%) }\end{array}$ & $\begin{array}{c}\text { Glucose }(\mathrm{mg} / \mathrm{dL}) \\
(\mathrm{CSF} / \text { serum, \%) }\end{array}$ & $\begin{array}{l}\text { Protein } \\
(\mathrm{mg} / \mathrm{dL})\end{array}$ & $\begin{array}{c}\text { Culture } \\
\text { (B and/or C) }\end{array}$ & BMS & Neurologic complication \\
\hline 1 & $35(7)$ & $46 / 75(61)$ & 168.1 & GBS (C) & 2 & - \\
\hline 2 & $129(87)$ & $63 / 123(51)$ & 91.9 & GBS (C) & 2 & - \\
\hline 3 & $154(82)$ & $60 / 97(62)$ & 50.0 & GBS (C) & 2 & Seizure, multifocal hematoma (Brain MRI) \\
\hline 4 & $75(49)$ & $75 / 145(52)$ & 53.7 & MRSA (B,C) & 0 & - \\
\hline 5 & $94(54)$ & $59 / 97(61)$ & 72.4 & Streptococcus mitis (B) & 1 & - \\
\hline 6 & $76(75)$ & $11 / 151(7)$ & 799.4 & GBS $(B, C)$ & $2+2$ & Seizure \\
\hline 7 & $615(82)$ & $52 / 112(46)$ & 95.1 & S.epidermidis (B) & 2 & - \\
\hline 8 & $2,700(92)$ & $10 / 128(8)$ & 779 & E.cloacae (C) & 4 & $\begin{array}{l}\text { Seizure, multiple abscess, encephalitis, ventri- } \\
\text { culitis (Brain MRI) }\end{array}$ \\
\hline 9 & $270(70)$ & $48 / 194(25)$ & 90.0 & Gamella haemolysans (B) & 2 & - \\
\hline 10 & $100(7)$ & $45 / 79(57)$ & 68.0 & S.cohnii $(\mathrm{B}, \mathrm{C})$ & 0 & - \\
\hline 11 & $37(26)$ & $49 / 89(55)$ & 86.0 & S.epidermidis (B) & 1 & - \\
\hline 12 & $28(95)$ & $62 / 97(64)$ & 94.7 & GBS (C) & $1+2$ & - \\
\hline 13 & $34(95)$ & $61 / 104(59)$ & 89.0 & S.epidermidis (B) & 1 & - \\
\hline
\end{tabular}

Plus-minus values are mean \pm SD.

Abbreviations: WBC, white blood cell count; BMS, bacterial meningitis score; B, blood; C, CSF.

group vs. $0.5 \pm 0.5$ in aseptic group, $P<0.001)$.

The analysis on the clinical manifestation of those 13 infants who were categorized into bacterial group revealed that eight infants presented positive for CSF examination, eight infants presented positive for blood culture, and three infants presented positive for both CSF examination and blood culture. The identified bacterial strain was mostly composed of Streptococcus agalatiae $(\mathrm{n}=5,38.5 \%)$ and Staphylococcus epidermidis $(\mathrm{n}=4$, 30.8\%); and Streptococcus mitis, Enterobacter cloacae, Gamella haemolysans, and Staphylococcus cohnii was identified from one infant each. Two infants (patient 6 and 12) presented positive for CSF gram stain. BMS was revealed as 0 point in two infants and two points in eight infants. The neurological complications including encephalitis, intracranial hematoma, brain abscess, ventriculitis, and seizure were found from three infants (Table 5).

\section{DISCUSSION}

Infections are frequent and important cause of morbidity and mortality in the neonatal period. Neonatal meningitis especially is one of the most severe infections in the neonatal period.

In the first prospective, national neonatal surveillance study in the United Kingdom over the period 1985-1987, low birth weight and prematurity was found to be associated with a tenfold higher incidence of meningitis and in the 10 years later repeated study which was conducted over 1996-1997, gestational age $<33$ weeks remained a significant risk factor ${ }^{15,16)}$. But in our study, there was no significant difference of incidence according to gestational age at birth, not only in total meningitis population but between bacterial and aseptic groups statistically. It is thought to be difficult to be compared in this study due to large intergroup difference in the birth rate per gestational age. In this study, the results of the blood examination and the cerebrospinal fluid examination were analyzed and compared. Despite that platelet count was lower, and serum total protein and albumin were higher in aseptic group compared to bacterial group with statistical significance, no clinical significance was found as majority of these values from both groups were within the normal reference range. While Cho et al. ${ }^{17)}$ conducted a study comparing bacterial and aseptic meningitis in neonates and reported significant intergroup differences in blood examination including CRP, however, no such significant difference was observed in this study. Meanwhile, the liver function test revealed higher ALT in aseptic group, and this is thought to be in the line with the report from Adams and Hubscher ${ }^{18)}$ that the liver function can be damaged by immune responses in infectious disease including viral diseases.

The BMS, a clinical prediction measure for identification of children with CSF pleocytosis who are at very low risk of bacterial meningitis, had been developed and validated in the study of Nigrovic et al. ${ }^{5)}$ In the study, CSF gram stain, seizure at or before 
presentation, peripheral absolute neutrophil count (ANC), CSF ANC, and CSF protein concentration showed a significant difference between bacterial meningitis group and aseptic meningitis group; and these were chosen for the components of BMS. However, despite that intergroup difference was observed in CSF ANC, no significant difference was found in peripheral ANC and CSF protein. The positive finding in CSF gram stain was found from two patients in bacterial group only. There was no intergroup difference found in seizure.

Due to the immune system that is not fully developed, the occurrence of meningitis is higher in neonates compared to any other age; however, no consensus on the application of BMS in neonatal meningitis has been established in many previous studies.

In the validation study of BMS on 2002, of the 77 patients between 29 to 60 days of age, BMS accurately identified the three patients with bacterial meningitis ${ }^{5}$. But, in the study on 2007, BMS misclassified two patients with bacterial meningitis as having aseptic meningitis and both of them were infants between one and two months old with Escherichia coli meningitis and urinary tract infections, but with negative urinalysis at presentation ${ }^{6}$. We identified 70 infants with diagnosed meningitis, and about $18.5 \%$ of them had bacterial meningitis. Though the mean of the BMS was significantly higher in bacterial meningitis group than aseptic meningitis group, the positive predictive value of a $B M S=0$ for aseptic meningitis was not perfect $(93.3 \%$, $28 / 30$ ). But the positive predictive value and the specificity of a BMS $\geq 2$ for bacterial meningitis was $100 \%$.

Meningitis is difficult to diagnose clinically in neonatal period because its features may be non-specific. So even when patients in this age group are suspected sepsis, they routinely hospitalized and evaluated for CSF. After then, they treated with antibiotics until the result of CSF culture had been confirmed ${ }^{19)}$. The development of newer antibiotics and intensive care resulted in a decline in mortality of bacterial meningitis to less than $10 \%$ in infancy $^{3}$. In contrast, the incidence of neurological morbidity in infants who survive bacterial meningitis has no declined and rages from $20-58 \%$, dependent on the pathogen ${ }^{3,4)}$. Under clinical background described above, in neonates, distinguishing who are at high risk of bacterial meningitis to provide prompt management and identify those who warrant long-term follow up and early intervention would be valuable. In the same context, we focused on positive predictive value and the specificity of a BMS $\geq 2$ for bacterial meningitis rather than the negative predictive value of a score of 0 for bacterial meningitis and the result was encouraging. However, as bacterial meningitis is a disease that we cannot afford to miss, especially among the neonates, this study concluded that the high BMS score can be helpful in diagnosing bacterial meningitis but the low score cannot rule out bacterial meningitis. So, its diagnostic value is just 'adjunctive'.

There are several limitations in this study. First of all, only two infants of the entire subjects were positive for CSF gram stain; thereby this study had small number of subjects with higher BMS, and consequently the sensitivity of BMS $\geq 2$ for bacterial meningitis might be measured relatively lower. This is distinct from what have revealed in numerous existing studies; the positive CSF gram stain among other components of BMS has the greatest significance in prediction of the bacterial meningitis ${ }^{5)}$. Next, there is limitation in generalization of the results from this study and its statistical significance is weak due to small number of study subjects and high incidence of bacterial meningitis than general pediatric population since this study was based on the infants who were admitted to NICU in one tertiary hospital. Therefore, the results of this study needs to be interpreted with caution and prospective studies with larger scale are required to support the results in this study.

Despite that the use of BMS for sorting aseptic meningitis might be risky as previous studies cautioned, the results of this study indicated that the use of high BMS for sorting bacterial meningitis might be helpful in prompt initiation of antibiotics medication and keeping alert to any neurological manifestations.

\section{ACKNOWLEDGEMENT}

This research was supported by Basic Science Research Program through the National Research Foundation of Korea (NRF) funded by the Ministry of Education (NRF-2014R1A1A2060062)

\section{REFERENCES}

1) Kim KS. Acute bacterial meningitis in infants and children. Lancet Infect Dis 2010;10:32-42.

2) Pong A, Bradley JS. Bacterial meningitis and the newborn infant. Infect Dis Clin North Am 1999;13:711-33, viii.

3) Harvey D, Holt DE, Bedford H. Bacterial meningitis in the newborn: a prospective study of mortality and morbidity. Semin Perinatol 1999;23:218-25. 
4) Klinger G, Chin CN, Beyene J, Perlman M. Predicting the outcome of neonatal bacterial meningitis. Pediatrics 2000;106: 477-82.

5) Nigrovic LE, Kuppermann N, Malley R. Development and validation of a multivariable predictive model to distinguish bacterial from aseptic meningitis in children in the post-Haemophilus influenzae era. Pediatrics 2002;110:712-9.

6) Nigrovic LE, Kuppermann N, Macias CG, Cannavino CR, Moro-Sutherland DM, Schremmer RD, et al. Clinical prediction rule for identifying children with cerebrospinal fluid pleocytosis at very low risk of bacterial meningitis. JAMA 2007;297: 52-60.

7) Piérart J, Lepage P. Value of the 'Bacterial Meningitis Score' (BMS) for the differential diagnosis of bacterial versus viral meningitis. Rev Med Liege 2006;61:581-5.

8) Dubos F, Lamotte B, Bibi-Triki F, Moulin F, Raymond J, Gendrel $D$, et al. Clinical decision rules to distinguish between bacterial and aseptic meningitis. Arch Dis Child 2006;91:647-50.

9) Dubos F, De La Rocque F, Levy C, Bingen E, Aujard Y, Cohen R, et al. Sensitivity of the bacterial meningitis score in 889 children with bacterial meningitis. J Pediatr 2008;152:378-82.

10) Dubos F, Korczowski B, Aygun DA, Martinot A, Prat C, GalettoLacour A, et al. Distinguishing between bacterial and aseptic meningitis in children: European comparison of two clinical decision rules. Arch Dis Child 2010;95:963-7.

11) Agüero G, Davenport MC, Del Valle Mde L, Gallegos P, Kannemann AL, Bokser V, et al. Validation of a clinical prediction rule to distinguish bacterial from aseptic meningitis. Arch Ar- gent Pediatr 2010;108:40-4.

12) Tuerlinckx D, El Hayeck J, Van der Linden D, Bodart E, Glupczynski Y. External validation of the bacterial meningitis score in children hospitalized with meningitis. Acta Clin Belg 2012; 67:282-5.

13) Gaschignard J, Levy C, Romain O, Cohen R, Bingen E, Aujard Y, et al. Neonatal bacterial meningitis: 444 cases in 7 years. Pediatr Infect Dis J 2011;30:212-7.

14) Barone MA. Laboratory values. In: McMillan JA, DeAngelis CD, FeiginRD, Warshaw JD, editors. Oski's pediatrics: principles and practice. 3rd ed. New York, NY: Lippincott Williams \& Wilkins. 1999:2225.

15) de Louvois J, Blackbourn J, Hurley R, Harvey D. Infantile meningitis in England and Wales: a two year study. Arch Dis Child 1991;66:603-7.

16) Holt DE, Halket S, de Louvois J, Harvey D. Neonatal meningitis in England and Wales: 10 years on. Arch Dis Child Fetal Neonatal Ed 2001;84:F85-9.

17) Cho SD, Kang B, Park SH, Sung HU, Jun YH, Hong YJ, et al. The comparative analysis of bacterial and aseptic meningitis in neonates. J Korean Child Neurol Soc 2012;20:1-8.

18) Adams DH, Hubscher SG. Systemic viral infections and collateral damage in the liver. Am J Pathol 2006;168:1057-9.

19) Kwon HE, Lee YM, Lee JS, Kim HD, Kang HC. Clinical presentations and bacterial meningitis score in children with cerebrospinal fluid (CSF) pleocytosis. J Korean Child Neurol Soc 2013; 21:46-52. 